\title{
BMR
}

\section{Characterization, molecular cloning, and expression analysis of Ecsit in the spinyhead croaker, Collichthys lucidus}

\author{
W. Song, K.J. Jiang, F.Y. Zhang, J. Wang and L.B. Ma \\ East China Sea Fisheries Research Institute, Chinese Academy of Fishery Sciences, \\ Shanghai, China \\ Corresponding author: L.B. Ma \\ E-mail: swift83@sina.com \\ Genet. Mol. Res. 15 (1): gmr.15017193 \\ Received August 10, 2015 \\ Accepted October 18, 2015 \\ Published January 8, 2016 \\ DOI http://dx.doi.org/10.4238/gmr.15017193
}

ABSTRACT. Evolutionarily conserved signaling intermediate in Toll pathways (Ecsit) is reported to play an essential role in innate immunity, embryogenesis, and assembly or stability of the mitochondrial complex I. In this study, the full-length cDNA of Ecsit was cloned from the spinyhead croaker Collichthys lucidus based on the expressed sequence tags from our cDNA library constructed using the SMART technique. The CDNA was $1669 \mathrm{bp}$ long, including a $5^{\prime}$-terminal untranslated region (UTR) of 121 $\mathrm{bp}$, a 3 '-terminal UTR of $183 \mathrm{bp}$, and an open reading frame of $1365 \mathrm{bp}$ encoding a 454-amino acid polypeptide. The estimated molecular weight of C. lucidus Ecsit (ClEcsit) was $52.50 \mathrm{kDa}$ with an isoelectric point of 6.14, and contained a typical Ecsit domain that is conserved in other Ecsits. Multiple alignment of CIEcsit with other selected Ecsits suggested that some amino acid residues were highly conserved. Phylogenetic analysis indicated that ClEcsit was more similar to its identities in Sciaenidae and grouped with Ecsits from other Perciformes. Quantitative real-time reverse transcription PCR analysis revealed broad expression 
of CIEcsit and the transcript was strongly expressed in the gill and weakly expressed in other tissues.

Key words: Collichthys lucidus; Ecsit; Quantitative real-time PCR; Tissue expression

\section{INTRODUCTION}

Evolutionarily conserved signaling intermediate in the Toll signaling pathway (Ecsit) was first reported in 1999 and was later shown to play an important role in innate immunity, embryogenesis, and mitochondria-related functions (Kopp et al., 1999; Xiao et al., 2003; Vogel et al., 2007). Research has shown that Ecsit constitutes a molecular link between the Toll-like receptor (TLR) signaling pathway and the bone morphogenetic protein (BMP) pathway, which have roles in cell growth, division, migration, and apoptosis (Takeda and Akira, 2004a; Haynes et al., 2007; Frandsen et al., 2008). TLRs recognize pathogen-associated molecular patterns and activate the expression of NF-KB and AP-1 transcription factors via TAK1 or mitogen-activated protein kinase-1 (MEKK-1) (Moustakas and Heldin, 2003; Vogel et al., 2007). In addition, tumor necrosis factor receptor-associated factor 6 (TRAF6) is an early component of both cascades (Kopp et al., 1999). Ecsit can interact with TRAF6, which then interacts with a kinase, and thus participates in the Toll pathway. It can also interact with MEKK-1 to activate both NF-KB and AP-1 (Kopp et al., 1999). In short, Ecsit works as an intermediate in the TLR signaling pathway and links TRAF6 and MEKK-1. In the BMP pathway, BMP4 plays a pivotal role in gastrulation of the mouse embryo and signals through Bmpr1a, a type I BMP receptor, to up-regulate the expression of target genes (Tang et al., 1998; Lu et al., 2001). In addition, signaling by BMP receptors is mainly mediated by Smad proteins (Xiao et al., 2003). Ecsit can function as a cofactor for Smad1 and Smad4, and binds to the promoters of specific BMP target genes such as TIx2 (Xiao et al., 2003). Therefore, Ecsit is considered a signal-intersecting protein downstream of these two important signaling pathways. Furthermore, Ecsit also functions in the mitochondria by interacting with the molecular chaperone NDUFAF1 and functioning in the assembly of mitochondrial complex I (NADH:ubiquinone oxidoreductase) (Vogel et al., 2007).

Although Ecsit is multifunctional and is important for mammals, little is known about this protein in teleost fishes. Ecsit has not yet been identified in Collichthys lucidus. C. lucidus is a small economically important sciaenid species, and recent research on this species has mainly focused on its mitogenome, microsatellites, and auxology. More studies about Ecsit in C. lucidus and in other fishes are needed. The aim of the present study was to characterize the full-length cDNA of Ecsit in C. lucidus (ClEcsit), to deduce its amino acid sequence, and to determine its relative expression in different tissues, in an attempt to clarify the potential role of Ecsit in the Toll and BMP signaling pathways in C. lucidus.

\section{MATERIAL AND METHODS}

\section{Materials and reagents}

Healthy spinyhead croaker $C$. lucidus averaging $20 \pm 5 \mathrm{~g}$ in weight were collected from Ningde, China. Different tissues, including the gill, kidney, liver, brain, muscle, spleen, heart, 
and hemocytes were collected and immediately preserved in liquid nitrogen for RNA extraction. Hemocytes were withdrawn with a needle from the tail of $C$. lucidus into a syringe containing precooled $\left(-4^{\circ} \mathrm{C}\right)$ anticoagulant $(0.45 \mathrm{M} \mathrm{NaCl}, 0.1 \mathrm{M}$ glucose, $30 \mathrm{mM}$ trisodium citrate, $26 \mathrm{mM}$ citric acid, and $10 \mathrm{mM}$ EDTA, $\mathrm{pH} 4.6)$ at a volume ratio of $1: 1$, and then pelleted by centrifugation (8000 rpm) (Allegra ${ }^{\mathrm{TM}}$ 64R Centrifuge, BECKMAN COULTER, USA) at $4^{\circ} \mathrm{C}$ for $10 \mathrm{~min}$.

\section{cDNA library construction}

A C. lucidus cDNA library was constructed using a SMART ${ }^{\mathrm{TM}}$ CDNA Library Construction Kit (Clontech, Palo Alto, CA, USA). After searching the EST library, an EST highly similar to a previously identified Ecsit was selected for the further cloning of CIEcsit cDNA.

\section{Total RNA extraction and first-strand cDNA synthesis}

Total RNA was isolated from the gill using Unizol Reagents (Biostar, Shanghai, China) following the manufacturer protocol, and then stored at $-80^{\circ} \mathrm{C}$. The quality and concentration was checked by agarose gel electrophoresis and spectrophotometry (DU 800, BECKMAN COULTER).

First-strand cDNA synthesis was generated using Moloney murine leukemia virus reverse transcriptase (Promega Corporation, Madison, WI, USA) to transcribe poly(A) mRNA with Oligo-dT and random 6-mer primers. The reaction conditions were as recommended by the manufacturer.

\section{3'-RACE and 5'-RACE}

The missing 5'- and 3'-ends of CIEcsit cDNA were obtained by the rapid amplification of cDNA ends (RACE) method, which was performed using a SMART'M RACE CDNA Amplification Kit (Clontech) according to the manufacturer instructions. Primers for 3'- and 5'-RACE were as follows: Ecsit-3GSP (5'-GGTCCCCACTCTATTCCGCCTAA-3') and Ecsit-5GSP (5'-TAGACTCTTTGTCCACCCGCTCA-3').

\section{Sequence analysis}

Identity searches for nucleotide and protein sequences were performed using the BLAST algorithm at NCBI (http://www.ncbi.nlm.nih.gov/). The deduced amino acid sequence was analyzed with the Expert Protein Analysis System (http://www.expasy.org/). Amino acid sequences from various species were retrieved from the NCBI GenBank database and analyzed using the Vector NTI Suite 11.0, Clustal W Multiple Alignment program (http://www.ebi.ac.uk/clustalw/). A neighborjoining phylogenetic tree was constructed using the MEGA software version 4.1 and the confidence level in the generated tree was obtained using 1000 bootstraps.

\section{Quantitative real-time PCR (qRT-PCR) analysis of CIEcsit in various tissues}

qRT-PCR was performed to study the tissue distribution of Ecsit in C. lucidus. Total RNA (1 mg) was reverse transcribed with the ReverTra Ace qPCR RT Kit (TOYOBO Co., Ltd., Osaka, Japan) to generate first-strand CDNA. The product was diluted $1: 10$ and stored at $-20^{\circ} \mathrm{C}$ until quantitative real-time PCR analysis was performed. A pair of $18 S$ rRNA primers designed from 
the 18S rRNA sequence deposited in NCBI GenBank (GenBank accession No. JN211725.1) were used as the internal control, 18s-RT-F (5'-GCCTGAATACCGCAGCTAGGAATAA-3') and 18s-RT-R (5'-TTTCACCTCTAG CGGCACAATACG-3'). Expression levels were calculated by the standard curve method. The SYBR Green qRT-PCR assay using Power SYBR Green PCR Master Mix (Applied Biosystems, Foster City, CA, USA) was carried out in an ABI Step One Plus Detection system (Applied Biosystems). Amplifications were performed on a 96-well plate in a $20-\mu \mathrm{L}$ reaction volume containing $10 \mu \mathrm{L}$ SYBR Premix Taq TM, $0.8 \mu \mathrm{L}$ PCR forward primer $(10 \mathrm{mM}), 0.8 \mu \mathrm{L}$ PCR Reverse Primer (10 mM), $0.4 \mu \mathrm{L}$ ROX Reference Dyel, $2.0 \mu \mathrm{L}$ cDNA template, and $6.0 \mu \mathrm{L}$ diethylpyrocarbonate water. The reaction process for SYBR Green qRT-PCR was 10 min at $94^{\circ} \mathrm{C}$, followed by 45 cycles at $94^{\circ} \mathrm{C}$ for $15 \mathrm{~s}$ and $60^{\circ} \mathrm{C}$ for $1 \mathrm{~min}$, and elongation at $72^{\circ} \mathrm{C}$ for $10 \mathrm{~min}$. Primers used to amplify Ecsit were Ecsit-RT-F (5'-GACCAAGCCACCCTCAATCAGT-3') and Ecsit -RT-R (5'-CGGCGTTTAGGCGGAATAG-3').

\section{RESULTS AND DISCUSSION}

The Toll signaling pathway represents a primary line of defense against invading pathogens in the immune system of mammals (Armant and Fenton, 2002; Roach et al., 2005; Takeda and Akira, 2004b). Previous research has shown that Ecsit is a component of the Toll pathway that functions as a regulator of MEKK-1 processing (Kopp et al., 1999). In recent years, many TLRs and MYD88 proteins (important adaptor proteins involved in the TLR signaling pathway) have been studied. For instance, MYD88 (Yao et al., 2009), TLR1 (Wang et al., 2013), TLR2 (Baoprasertkul et al., 2007a), TLR3 (Baoprasertkul et al., 2006), TLR4 (Jault et al., 2004), TLR5 (Baoprasertkul et al., 2007b), TLR7 and TLR8 (Qian et al., 2013), TLR9 (Franch et al., 2006), TLR20 and TLR21 (Baoprasertkul et al., 2007b; Rebl et al., 2007) have been identified and characterized in fishes. However, only a few Ecsits have so far been identified in species other than mammals.

Studies have confirmed that BMPs are members of the transforming growth factor $\beta$ (TGF $\beta$ ) superfamily, which plays critical roles during mouse embryogenesis, and BMP4 plays a pivotal role in the gastrulation of mouse embryos (Lu et al., 2001; Xiao et al., 2003). Ecsit is a cofactor for Smad1 and Smad4, and binds to the promoter of specific BMP target genes; therefore, it is likely to have an important role in BMP signaling. Although Ecsit intersects the downstream signaling of two important signaling pathways, the exact mechanism through which Ecsit interacts with these two pathways remains unclear. In 2011, West et al. (2011) reported that Ecsit could interact with TRAF6 in mitochondria, which led to ubiquitination and enrichment at the mitochondrial periphery, thus increasing the generation of mitochondrial and cellular reactive oxygen species, and contributing to the bactericidal activity of mouse macrophages. Based on our understanding of mitochondrial and immune functions, some researchers have suggested that Ecsit may be used as a biomarker for future therapies to halt or prevent inflammation, oxidative stress, and neurodegenerative disorders related to mitochondrial dysfunctions (Milward et al., 2007; Mattson, 2012; Soler-López et al., 2012).

\section{Cloning of ClEcsit}

The full-length cDNA fragment of CIEcsit was found to consist of 1669 bp (GenBank accession No. KP735927), with an open reading frame (ORF) of 1365 bp, a 121-bp 5'-UTR and a 183-bp 3'-UTR containing a poly(A) signal, and consensus polyadenylation signals (AATAAA) 16 bp upstream of the poly $(A)$ tails. Based on the deduced polypeptide sequence, the ORF should 
encode a putative protein of 454 amino acids with a predicted molecular weight of $52.50 \mathrm{kDa}$, a theoretical isoelectric point of 6.14 , and no predicted signal peptide. The full-length nucleotide sequence and the deduced amino acid sequence are shown in Figure 1.

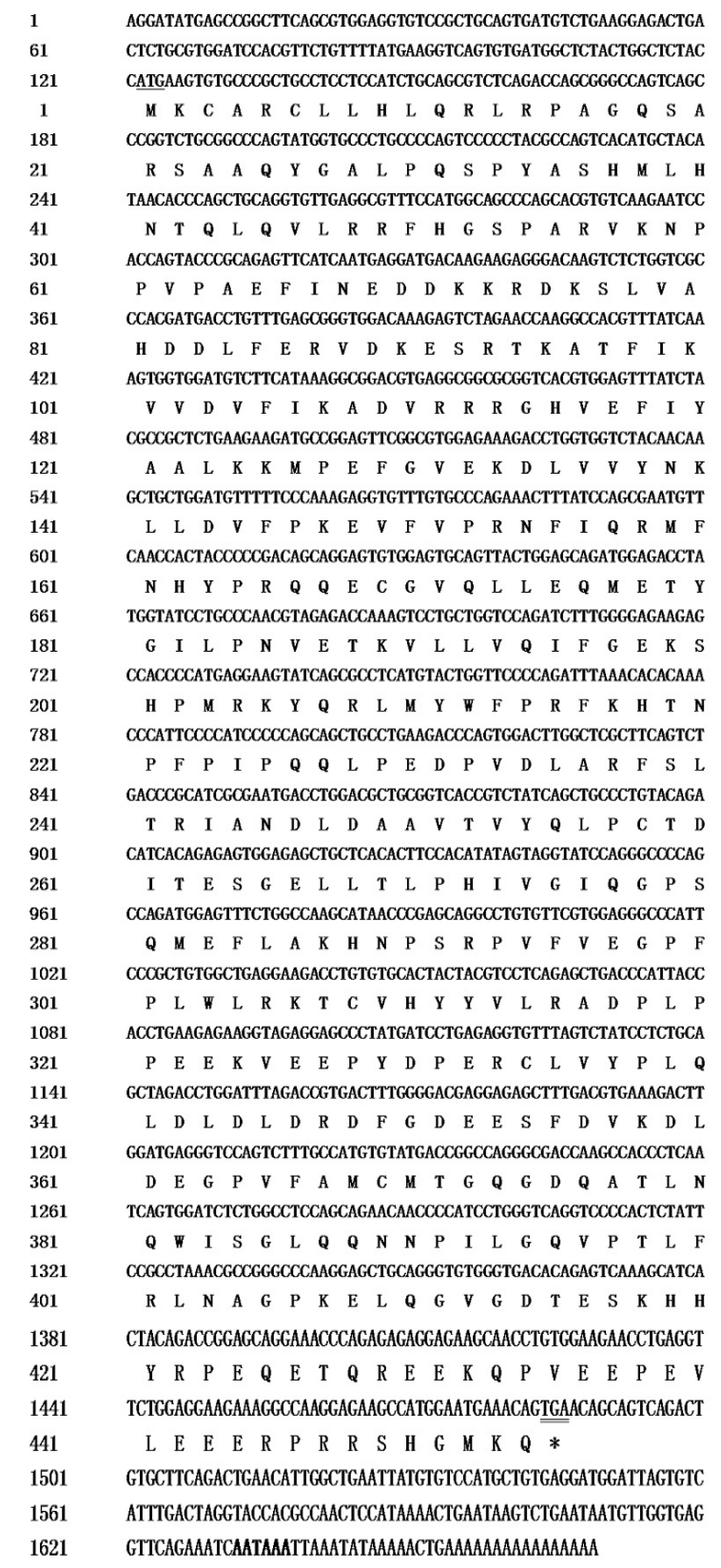

Figure 1. Nucleotide sequence and deduced amino-acid sequence of CIEcsit cDNA. The start (ATG) and stop (TAA) codons are underlined. The consensus polyadenylation signals (AATAAA) are bold. 
According to the deduced CIEcsit protein sequence, a classical ECSIT domain was identified between amino acids 39 and 276 by the SMART program. The CIEcsit ECSIT domain is similar to the typical domain structure of Ecsit in other species and in other fishes (Zhang et al., 2012), suggesting that CIEcsit may have a similar function in innate immunity, embryogenesis, and assembly or stability of mitochondrial complex I. In addition, five phosphorylation sites, including two casein kinase II sites, two protein kinase C sites, and a tyrosine kinase site, were annotated from the amino acid sequence.

\section{Sequence analysis}

After searching for sequence similarities, we found that the deduced amino acid sequence of ClEcsit shared higher identity with other known Ecsits. CIEcsit had overall similarity with the corresponding protein in Larimichthys crocea (GenBank accession No. XP_010741389.1) of 98\% (http://blast.ncbi.nlm.nih.gov/Blast.cgi). Multiple alignment of ClEcsit with other selected Ecsits from the NCBI database suggested that some amino acid residues were highly conserved in different species (Figure 2). They include Bos taurus (BtEcsit: AAI04573.1), Mus musculus (MmEcsit: AAF01219.1), Cynoglossus semilaevis (CsEcsit: XP_008326327.1), Poecilia formosa (PfEcsit: XP_007567928.1), Poecilia reticulata (PrEcsit: XP_008433156.1), Xiphophorus maculatus (XmEcsit: XP_005807990.1), Larimichthys crocea (LcEcsit: XP_010741389.1), Oreochromis niloticus (OnEcsit: XP_005463454.1), Maylandia zebra (MzEcsit: XP_004574366.1), Haplochromis burtoni (HbEcsit: XP_005945475.1), and Pundamilia nyererei (PnEcsit: XP_005753031.1). Furthermore, a phylogenic tree was constructed based on the amino acid sequences of selected species (the sequence used was the same as that used in the above Ecsit alignment) based on the neighbor-joining method by MEGA 4.1 (Figure 3). Phylogenetic analysis indicated that Ecsits from different species could be grouped into two clades, one containing Ecsits from fishes, and the other containing Ecsits from mammals. ClEcsit had higher identity with Ecsits of Sciaenidae such as L. crocea, and then grouped with Ecsits from other Perciformes. These results are consistent with the status of systematic evolution, indicating that the Ecsit gene could be a molecular index for systematic evolution.

\section{qRT-PCR analysis of CIMyD88 in various tissues}

Constitutive tissue expression of CIEcsit was confirmed by quantitative real-time PCR (Figure 4). The results showed that CIEcsit was broadly expressed, but at different levels, in the gill, kidney, liver, brain, muscle, spleen, heart, and hemocytes. The CIEcsit transcript was strongly expressed in the gill and weakly expressed in other tissues. In Crassostrea gigas, the CgEcsit transcript was detected in all tested tissues and the highest expression was found in the hemolymph (Zhang et al., 2012). However in Marsupenaeus japonicus, the MjEcsit1 transcript was detected in all the tissues tested, including the hemocyte and gill, and in hepatopancreatic, stomach, heart, intestinal, testicular, and ovarian tissues, with the highest expression detected in ovarian tissue (Ding et al., 2014). The observation that the Ecsit gene is expressed in diverse species at variable levels is probably because Ecsit has differing functions in different tissues in these species. 


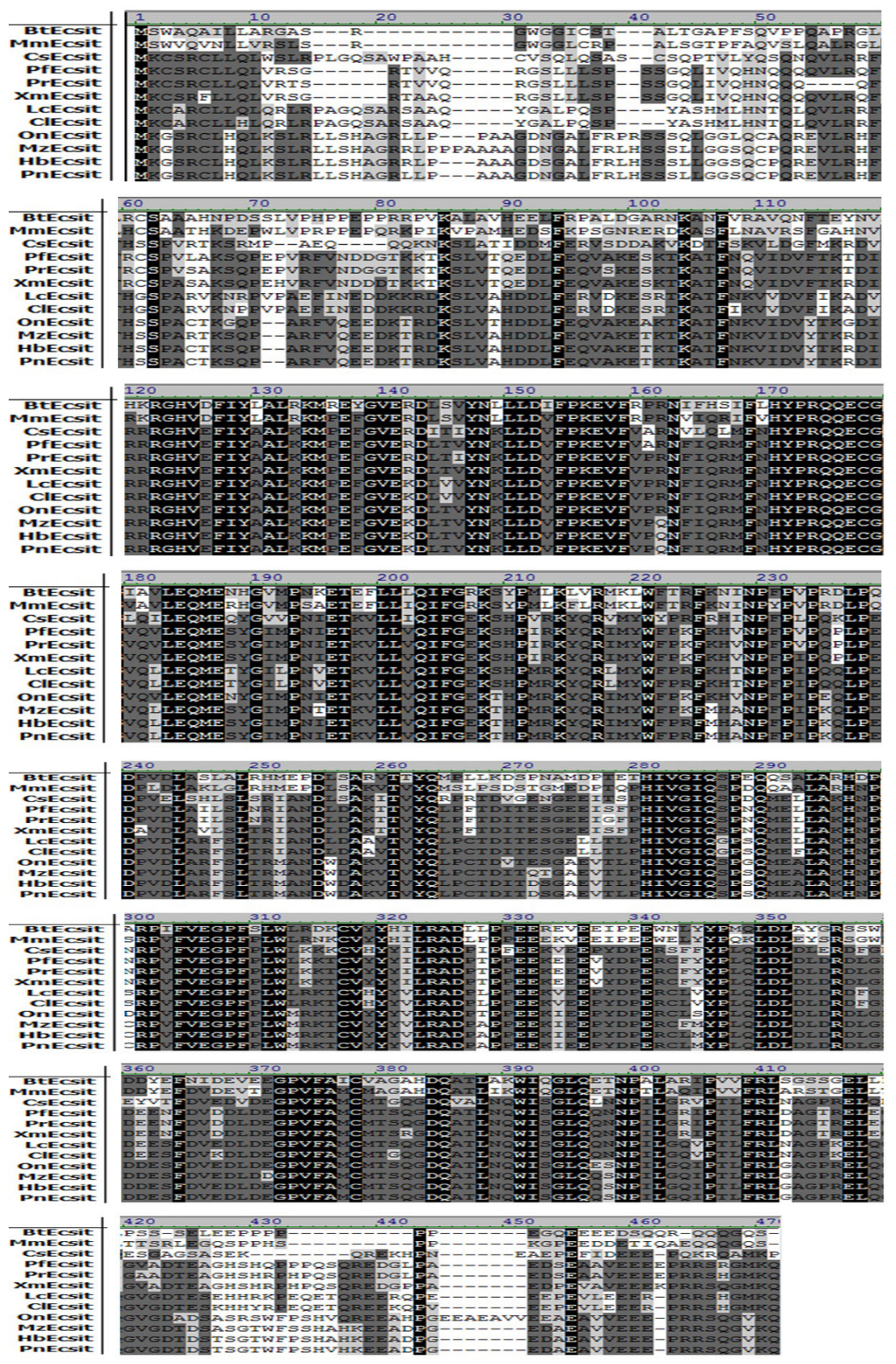

Figure 2. Multiple alignment of the amino acid sequence of CIEcsit with other selected Ecsits from other species. Gaps (-) were introduced to maximize the alignment. Relationships between residues are indicated as follows: nonsimilar residues, black letters on a white background; conserved residues, black letters on a dark gray background; block of similarity, black letters on a light gray background; identical residues, white letters on a black background. 


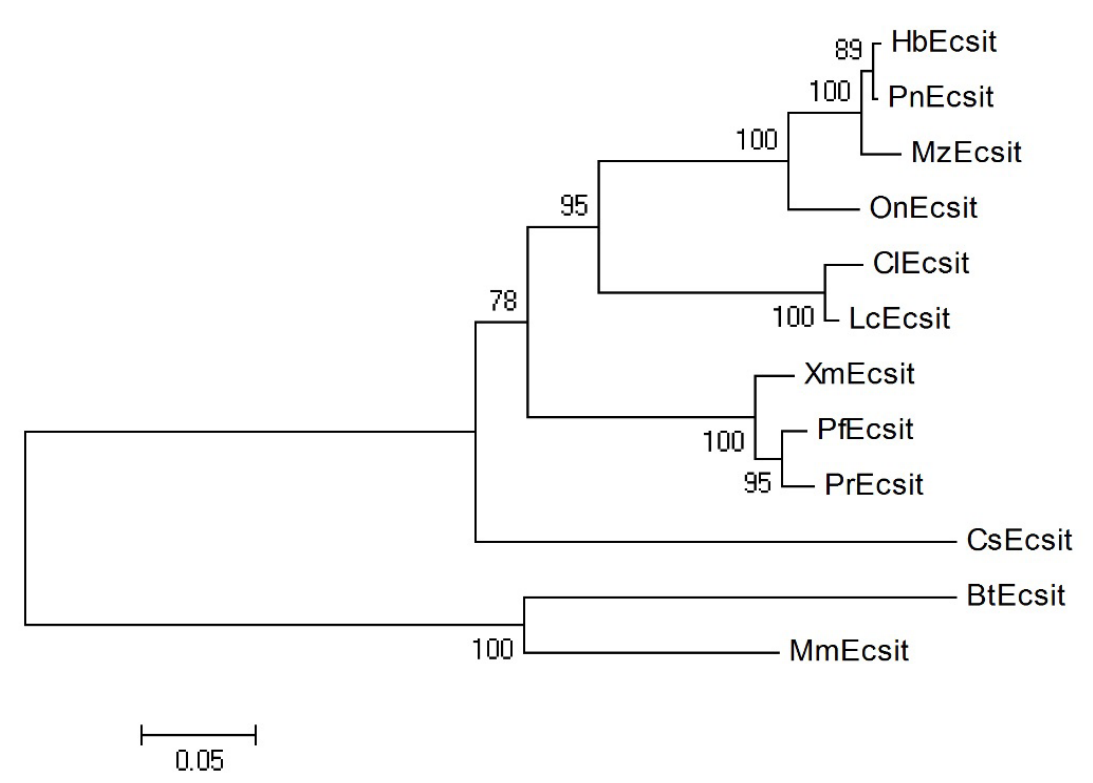

Figure 3. Evolutionary tree of Ecsit. The tree was constructed using the neighbor-joining algorithm in the MEGA 4.1 program based on multiple sequence alignment by Clustal W. The scale bar corresponds to estimated amino acid substitutions per site.

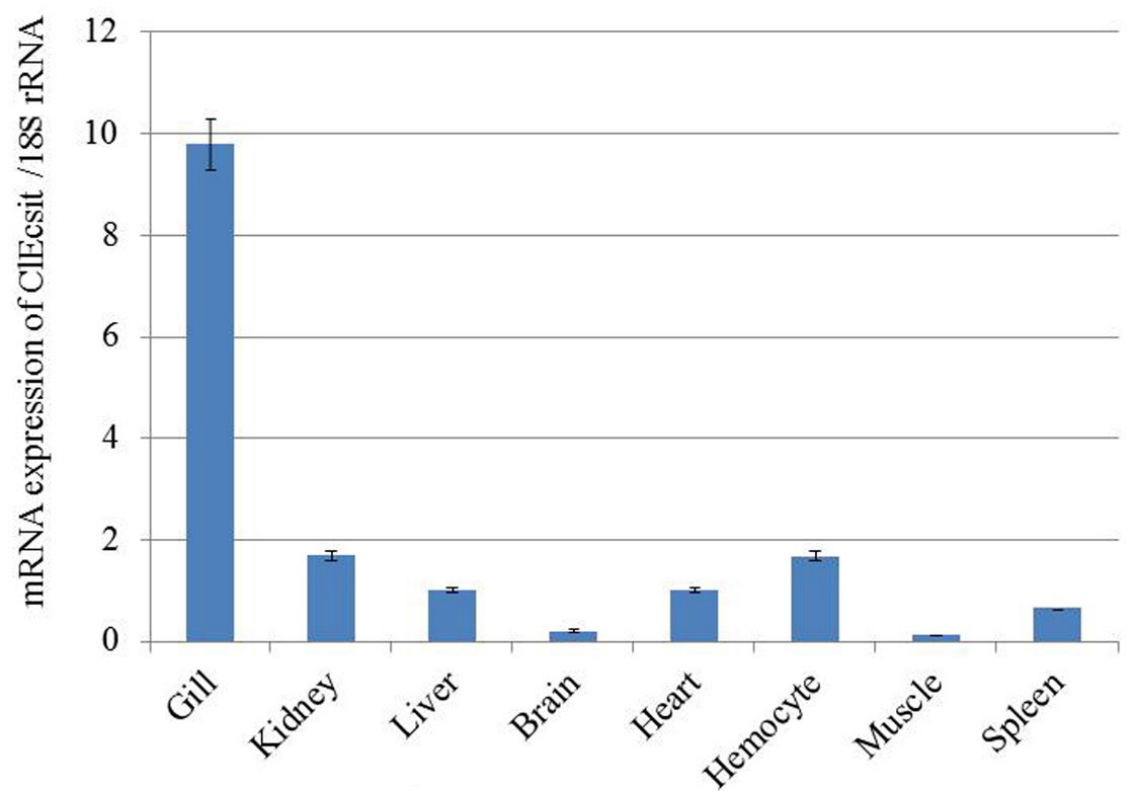

Figure 4. Relative expression levels of CIEcsit in different tissues of Collichthys lucidus, including the gill, kidney, liver, brain, heart, hemocyte, muscle, and spleen. The amount of MyD88 mRNA was normalized to the 18S rRNA transcript level. Data are reported as means $\pm S D$ of three repeated experiments. The $y$-axis represents the relative ratio of expression levels of CIEcsit/18S rRNA. 
In conclusion, in the present study, Collichthys lucidus CIEcsit was cloned and its expression investigated, and was found to belong to the conserved Ecsit family of proteins. qRT-PCR analysis showed that CIECsit was broadly expressed in all tissues, with the highest expression detected in the gill and the lowest detected in muscle.

\title{
Conflicts of interest
}

The authors declare no conflict of interest.

\section{ACKNOWLEDGMENTS}

\author{
Research supported by the Basic Research Fund for State-Level Nonprofit Research \\ Institutes of ESCFRI, CAFS (\#Dong2015M08).
}

\section{REFERENCES}

Armant MA and Fenton MJ (2002). Toll-like receptors: a family of pattern-recognition receptors in mammals. Genome Biol. 3 : S3011.http://dx.doi.org/10.1186/gb-2002-3-8-reviews3011

Baoprasertkul P, Peatman E, Somridhivej B and Liu Z (2006). Toll-like receptor 3 and TICAM genes in catfish: species-specific expression profiles following infection with Edwardsiella ictaluri. Immunogenetics 58: 817-830. http://dx.doi.org/10.1007/s00251-006-0144-z

Baoprasertkul P, Peatman E, Abernathy J and Liu Z (2007a). Structural characterisation and expression analysis of toll-like receptor 2 gene from catfish. Fish Shellfish Immunol. 22: 418-426.http://dx.doi.org/10.1016/j.fsi.2006.04.005

Baoprasertkul P, Xu P, Peatman E, Kucuktas H, et al. (2007b). Divergent Toll-like receptors in catfish (Ictalurus punctatus): TLR5S, TLR20, TLR21. Fish Shellfish Immunol. 23: 1218-1230.http://dx.doi.org/10.1016/j.fsi.2007.06.002

Ding D, Chen XW, Kang LH, Jiang HS, et al. (2014). Role of evolutionarily conserved signaling intermediate in Toll pathways (ECSIT) in the antibacterial immunity of Marsupenaeus japonicus. Dev. Comp. Immunol. 46: 246-254. http://dx.doi.org/10.1016/j.dci.2014.04.016

Franch R, Cardazzo B, Antonello J, Castagnaro M, et al. (2006). Full-length sequence and expression analysis of Toll-like receptor 9 in the gilthead seabream (Sparus aurata L.). Gene 378: 42-51.http://dx.doi.org/10.1016/j.gene.2006.04.025

Frandsen JL, Gunn B, Muratoglu S, Fossett N, et al. (2008). Salmonella pathogenesis reveals that BMP signaling regulates blood cell homeostasis and immune responses in Drosophila. Proc. Natl. Acad. Sci. USA 105: 14952-14957. http://dx.doi.org/10.1073/pnas.0808208105

Haynes T, Gutierrez C, Aycinena JC, Tsonis PA, et al. (2007). BMP signaling mediates stem/progenitor cell-induced retina regeneration. Proc. Natl. Acad. Sci. USA 104: 20380-20385.http://dx.doi.org/10.1073/pnas.0708202104

Jault C, Pichon L and Chluba J (2004). Toll-like receptor gene family and TIR-domain adapters in Danio rerio. Mol. Immunol. 40: 759-771.http://dx.doi.org/10.1016/.jmolimm.2003.10.001

Kopp E, Medzhitov R, Carothers J, Xiao C, et al. (1999). ECSIT is an evolutionarily conserved intermediate in the Toll/IL-1 signal transduction pathway. Genes Dev. 13: 2059-2071.http://dx.doi.org/10.1101/gad.13.16.2059

Lu CC, Brennan J and Robertson EJ (2001). From fertilization to gastrulation: axis formation in the mouse embryo. Curr. Opin. Genet. Dev. 11: 384-392.http://dx.doi.org/10.1016/S0959-437X(00)00208-2

Mattson MP (2012). An ECSIT-centric view of Alzheimer's disease. BioEssays 34: 526-527. http://dx.doi.org/10.1002/bies.201200058

Milward E, Johnstone D, Trinder D, Ramm G, et al. (2007). The nexus of iron and inflammation in hepcidin regulation: SMADs, STATs, and ECSIT. Hepatology 45: 253-256.http://dx.doi.org/10.1002/hep.21526

Moustakas A and Heldin CH (2003). Ecsit-ement on the crossroads of Toll and BMP signal transduction. Genes Dev. 17: 28552859.http://dx.doi.org/10.1101/gad.1161403

Qian T, Wang K, Mu Y, Ao J, et al. (2013). Molecular characterization and expression analysis of TLR 7 and TLR 8 homologs in large yellow croaker (Pseudosciaena crocea). Fish Shellfish Immunol. 35: 671-679.http://dx.doi.org/10.1016/j.fsi.2013.05.019

Rebl A, Siegl E, Köllner B, Fischer U, et al. (2007). Characterization of twin toll-like receptors from rainbow trout (Oncorhynchus mykiss): evolutionary relationship and induced expression by Aeromonas salmonicida salmonicida. Dev. Comp. Immunol. 31: 499-510.http://dx.doi.org/10.1016/j.dci.2006.08.007 
Roach JC, Glusman G, Rowen L, Kaur A, et al. (2005). The evolution of vertebrate Toll-like receptors. Proc. Natl. Acad. Sci. USA 102: 9577-9582.http://dx.doi.org/10.1073/pnas.0502272102

Soler-López M, Badiola N, Zanzoni A and Aloy P (2012). Towards Alzheimer's root cause: ECSIT as an integrating hub between oxidative stress, inflammation and mitochondrial dysfunction. Hypothetical role of the adapter protein ECSIT in familial and sporadic Alzheimer's disease pathogenesis. BioEssays 34: 532-541.http://dx.doi.org/10.1002/bies.201100193

Takeda K and Akira S (2004a). TLR signaling pathways. Semin. Immunol. 16: 3-9.http://dx.doi.org/10.1016/j.smim.2003.10.003

Takeda K and Akira S (2004b). Toll-like receptors in innate immunity. Int. Immunol. 17: 1-14.http://dx.doi.org/10.1093/intimm/dxh186

Tang SJ, Hoodless PA, Lu Z, Breitman ML, et al. (1998). The Tlx-2 homeobox gene is a downstream target of BMP signalling and is required for mouse mesoderm development. Development 125: 1877-1887.

Vogel RO, Janssen RJ, van den Brand MA, Dieteren CE, et al. (2007). Cytosolic signaling protein Ecsit also localizes to mitochondria where it interacts with chaperone NDUFAF1 and functions in complex I assembly. Genes Dev. 21: 615-624. http://dx.doi.org/10.1101/gad.408407

Wang K, Mu Y, Qian T, Ao J, et al. (2013). Molecular characterization and expression analysis of toll-like receptor 1 from large yellow croaker (Pseudosciaena crocea). Fish Shellfish Immunol. 35: 2046-2050.http://dx.doi.org/10.1016/j.fsi.2013.10.022

West AP, Brodsky IE, Rahner C, Woo DK, et al. (2011). TLR signalling augments macrophage bactericidal activity through mitochondrial ROS. Nature 472: 476-480.http://dx.doi.org/10.1038/nature09973

Xiao C, Shim JH, Klüppel M, Zhang SS, et al. (2003). Ecsit is required for Bmp signaling and mesoderm formation during mouse embryogenesis. Genes Dev. 17: 2933-2949.http://dx.doi.org/10.1101/gad.1145603

Yao CL, Kong P, Wang ZY, Ji PF, et al. (2009). Molecular cloning and expression of MyD88 in large yellow croaker, Pseudosciaena crocea. Fish Shellfish Immunol. 26: 249-255.http://dx.doi.org/10.1016/j.fsi.2008.10.014

Zhang LL, Li L and Zhang GF (2012). The first identification of molluscan Ecsit in the Pacific oyster, Crassostrea gigas, and its expression against bacterial challenge. Aquacult. Res. 43: 1071-1080.http://dx.doi.org/10.1111/j.1365-2109.2011.02910.x 